\title{
A DEM based tool for the safety analysis of masonry gravity dams
}

\author{
Eduardo M. Bretas ${ }^{\mathrm{a}, *}$, José V. Lemos ${ }^{\mathrm{a}}$, Paulo B. Lourenço ${ }^{\mathrm{b}}$ \\ a National Laboratory for Civil Engineering, Av. do Brasil, 101, 1700-066 Lisbon, Portugal \\ ${ }^{\mathrm{b}}$ Department of Civil Engineering, University of Minho, Portugal
}

\section{A R T I C L E I N F O}

\section{Article history:}

Received 6 May 2013

Revised 28 October 2013

Accepted 31 October 2013

Available online 4 December 2013

\section{Keywords:}

Masonry dams

Discrete elements

Stress analysis

Failure mechanisms

\begin{abstract}
A B S T R A C T
A numerical model for analysis of masonry gravity dams based on the Discrete Element Method is presented. The dam and the rock foundation are represented as block assemblies, using elementary 3- and 4node blocks. Complex block shapes are obtained by assembling the elementary blocks into macroblocks, allowing the model to be applied in various situations ranging from equivalent continuum to fully discontinuum analysis. A contact formulation was developed, which represents the interaction between macroblocks in terms of contacts established between elementary blocks, based on an accurate edge-edge approach. The main numerical aspects of the model are described, addressing in particular the contact creation and update procedures, and the numerical devices that support an efficient explicit solution algorithm. An application to the safety evaluation of an existing masonry dam is discussed, including stress analysis in the structure, and the assessment of sliding failure mechanisms, involving different paths in the vicinity of the dam-rock interface.
\end{abstract}

(C) 2013 Elsevier Ltd. All rights reserved.

\section{Introduction}

Structural analysis must use appropriate methods to achieve its final purposes. These methods should be capable of (i) modelling the geometrical and physical characteristics of the structure, in particular the discontinuities and joints, (ii) modelling the loads in an integrated manner, taking into account the interaction between the relevant phenomena involved, and (iii) evaluating the non-linear behaviour, particularly allowing the definition of failure mechanisms.

Masonry gravity dams should be understood as a system composed of the dam itself, the reservoir, and the rock mass foundation. The dam and the rock mass are heterogeneous and discontinuous media. The dam-rock interface is also a discontinuity which requires particular attention. The discontinuity surfaces control the behaviour of masonry dams, because they are weakness planes that determine the main mechanisms of failure. In addition, dams are subject to a wide variety of loads requiring an integrated approach since they are often correlated. These particular features make the majority of the available numerical tools, both commercial and scientific, not entirely suitable for modelling masonry gravity dams. In this context, the development of new analysis tools is required. Here, a tailored numerical implementation of the Discrete Element Method (DEM) for static, dynamic and hydromechanical analysis of masonry gravity dams is described.

\footnotetext{
* Corresponding author. Tel.: +351 218443 000; fax: +351 218443026.

E-mail addresses: ebretas@Inec.pt (E.M. Bretas), vlemos@lnec.pt (J.V. Lemos), pbl@civil.uminho.pt (P.B. Lourenço).
}

The Discrete Element Method was initially proposed as an alternative to the Finite Element Method (FEM) to address Rock Mechanics problems [1]. DEM was based on the representation of the discontinuous media as an assembly of blocks in mechanical interaction, thus differing from the standard FEM approach based on joint elements [2,3]. These numerical approaches have also been widely applied to masonry structures [e.g. 4]. The 2D code UDEC [5], which evolved from Cundall's pioneering work, has been used in several studies involving concrete dam foundations, mostly intending to assess failure mechanisms through the rock mass [e.g. 6-8]. Tatone et al. [9] performed a DEM analysis of sliding on the dam-rock interface, considering a detailed representation of the irregular geometry of this surface and the ensuing stress concentrations.

Discrete Element Method codes usually represent deformable blocks by discretizing them into an internal mesh of triangular uniform strain elements (e.g., [5]). The designation "discrete finiteelement method" $[10,17]$ is often applied to codes that allow the breakage of the block elements to simulate progressive failure processes. The model presented in this paper is based on DEM and was devised with three main requirements, implemented in a novel software tool fully developed by the authors. Firstly, it is intended to model in an integrated manner both the masonry dam and the rock foundation as components of a blocky system. Secondly, the software tool should provide a practical means to address both equivalent continuum and blocky models, using the same mesh. Finally, the tool needs to include all the features required in dam engineering analysis, such as water flow and pressures in the joints, reinforcement elements, such as passive or active anchors, 